\title{
Health profile of adolescent girls visiting obstetrics and gynecology department of tertiary care hospital
}

\author{
Rajal V. Thaker, Anuradha B. Madiya*, Hiral D. Chaudhari, \\ Jayesh D. Maru, Shyama B. Baranda
}

Department of Obstetrics and Gynecology, SCL Hospital, Smt NHL Municipal Medical College, Ahmedabad, Gujarat, India

Received: 08 September 2018

Accepted: 05 October 2018

*Correspondence:

Dr. Anuradha B. Madiya,

E-mail: rvtpds@gmail.com

Copyright: () the author(s), publisher and licensee Medip Academy. This is an open-access article distributed under the terms of the Creative Commons Attribution Non-Commercial License, which permits unrestricted non-commercial use, distribution, and reproduction in any medium, provided the original work is properly cited.

\begin{abstract}
Background: Gynecological problems of adolescents occupy a special space in the spectrum of gynecological disorders of all ages. In this study, an attempt has been made to review the health profile of adolescent girls visiting department of Obstetrics and Gynecology of a tertiary care hospital.

Methods: This observational study was conducted at a tertiary care teaching hospital during June 2014 to May 2016. Data was collected after due permission.

Results: Adolescent girls having gynecological problems were 2.3\%. Mean age of menarche was 12.5 years. Anemia was present in $89(62.7 \%)$. About $72(50.7 \%$ ) adolescent girls were having abnormal body mass index (BMI). Majority of girls $136(95.8 \%$ ) had menstrual problems. Leucorrhoea, Pelvic Inflammatory Disease (PID), ovarian mass, urinary problems, breast problems, injury to genital tract and sexual assault were present in 42(29.6\%), 24(16.9\%), $20(14.1 \%), 13(9.2 \%), 12(8.5 \%), 4(2.8 \%)$ and $1(0.7 \%)$ respectively.

Conclusions: A very small proportion of adolescent girls came to the hospital for health-related issues. Anemia was present in more than half of adolescent girls and almost half of adolescent girls were having abnormal BMI. Majority of adolescent girls had menstrual problems. Health education regarding normal physiology, various gynecological problems, importance of nutrition and exercise for adolescents is necessary.
\end{abstract}

Keywords: Adolescent health, Gynecological problems of adolescents, Menstrual problems in adolescents

\section{INTRODUCTION}

Adolescence is derived from the Latin word "adolescere", meaning, "to grow up". Adolescence is a period of enormous physical and psychological change for young girls. As per WHO, adolescence includes the age group of 10-19 years. $^{1}$ It is a psychological, cognitive and cultural maturation process that is initiated by biological changes of puberty that leads to maturation and growth of the body and mind. It is the most important period wherein the foundation of a responsible adult is laid.
Adolescence is a phase of stress, storms, adventures, rebellions, a time when gender roles are more and more strengthened. Adolescents represent $22 \%$ of the India's total population, in which female adolescents comprise $47 \%$ of the adolescent population. ${ }^{2}$

List of adolescent specific health problems include growth and nutritional disorders, reproductive and fertility health problems, substance abuse, accidents injuries, mental health problems and non-communicable diseases and have capacity to influence adult health status. 
Majority of these adolescent health challenges are interlinked and preventable. When an adolescent reaches the care center few of these problems co-exist but what will be visible and informed will be the recent, acute, compelling health problems and others shall be missed and unattended, with a high risk of non-relief, resurgence and worsening. Various factors such as embarrassment, privacy and confidentiality concerns, cultural factors, fear of medical procedures, judgmental attitude of provider, are usually barriers preventing adolescents from visiting a health care facility. Systematic adolescent health screening for holistic and integrated management shall be useful to manage such challenges.

Gynecological problems of adolescents occupy a special space in the spectrum of gynecological disorders of all ages. This is because of the physical nature of the problems which are so unique, special, and specific for the age group, and also because of the associated and psychological factors which are very important in the growth and psychological remodeling of someone in the transition between childhood and womanhood. Yet adolescent gynecology is a subspecialized area of gynecology, which has still not been explored optimally.

In this study, an attempt has been made to review the health profile of adolescent girls visiting department of Obstetrics and Gynecology of our institute. This study was undertaken to assess demographic details (age, residential area, socioeconomic, marital and educational status), to assess the proportion of gynecological problems and to study various types of gynecological problems in adolescent girls.

\section{METHODS}

This retrospective observational study was conducted at a tertiary care teaching hospital after due permission during June 2014 to May 2016. During this period, out of 8149 patients having gynecological problems, 189 girls were in age group 10-19 years. Out of these 189, we have collected data of 142 girls, as in 47 girls follow up was lost. Data was collected from hospital records. Data was analyzed by appropriate statistical tool.

\section{Inclusion criteria}

- Adolescent girls in age group of 10-19 years having gynecological problems.

\section{Exclusion criteria}

- Adolescent girls in 10-19 years age group having pregnancy and its complications.

Detailed history was taken, and examination was carried out in each patient maintaining privacy, confidentiality and non-judgmental attitude. Thorough gentle general examination including height, weight, built, pallor, edema, secondary sexual characters, hair distribution, followed by systemic examination was done. Local genital examination was done in relevant cases by inspection of labia, condition of hymen. Per speculum and per vaginal examinations were not done in adolescent girls who were not sexually active. Per rectal examination was done as and when required. Patients were subjected to routine investigations and specific investigations (such as hormonal assessment, ultrasonography, MRI, CT scan etc) were done as and when indicated.

\section{RESULTS}

During the study period, 8149 patients came to our institute with gynecological problems. Out of them, only 189 were in adolescent age group. Hence, adolescent girls having gynecological problems were $2.3 \%$. Out of 189 patients, we have collected data of 142 girls, as in 47 girls follow up was lost.

Table 1: Adolescent gynecological problems and demographic details $(\mathrm{N}=142)$.

\begin{tabular}{|lll|}
\hline Demographic details & No. & Percentage \\
\hline Age (in completed years) & & \\
\hline $10-12$ & 7 & 4.9 \\
\hline $13-15$ & 34 & 23.9 \\
\hline $16-19$ & 101 & 71.1 \\
\hline Residence & & \\
\hline Urban & 115 & 81.0 \\
\hline Rural & 27 & 19.0 \\
\hline Level of education & & \\
\hline Illiterate & 06 & 4.2 \\
\hline Primary & 29 & 20.4 \\
\hline Secondary & 48 & 33.8 \\
\hline Higher secondary & 41 & 28.9 \\
\hline College (studying) & 18 & 12.7 \\
\hline Socioeconomic class & & \\
\hline Low & 60 & 42.3 \\
\hline Middle & 73 & 51.4 \\
\hline High & 9 & 6.3 \\
\hline Marital status & & \\
\hline Unmarried & 97 & 68.3 \\
\hline Married & 45 & 31.7 \\
\hline
\end{tabular}

As shown in Table 1, maximum percentage of girls 101 $(71.1 \%)$ belonged to the age group of $16-19$ years. Minimum percentage of girls belonged to age group of 10-12 years 7 (4.9\%). Majority of girls 115 (81.0\%) were from urban area and only $6(4.2 \%)$ were illiterate, whereas $29(20.4 \%)$ had primary education, 48 (33.8\%) had secondary education, $41(28.9 \%)$ had higher secondary education and $18(12.7 \%)$ were studying for graduate degree.

The proportion of adolescent gynecological problems was highest, in $73(51.4 \%)$ among middle socioeconomic class and lowest, $9(6.3 \%)$ among high socioeconomic class. In present study, $45(31.7 \%)$ married and 97 $(68.3 \%)$ unmarried girls visited our hospital with 
adolescent gynecological problems. As shown in Table 2, majority had attained menarche by 12 years in 40 $(31.5 \%)$, followed by at 13 years in $34(26.8 \%)$ and at 11 years in $26(20.5 \%)$.

Table 2: Age of menarche $(\mathrm{N}=127)$.

\begin{tabular}{|c|c|c|}
\hline Age (in completed years) & No. & Percentage \\
\hline 11 & 26 & 20.5 \\
\hline 12 & 40 & 31.5 \\
\hline 13 & 34 & 26.8 \\
\hline 14 & 21 & 16.5 \\
\hline 15 & 5 & 3.9 \\
\hline 16 & 1 & 0.8 \\
\hline Mean age of menarche & 12.5 & \\
\hline
\end{tabular}

Mean age of menarche was 12.5 years. In present study, $127(89.4 \%)$ girls attained menarche by the age of 16 years. Primary amenorrhoea was present in $9(6.6 \%)$. Out of 6 girls, who were yet to attain menarche, 3 patients came at age of 11 years and one each of at the age of 12 , 14 , and 15 , with complains of delayed menarche, injury and sexual assault respectively.

Table 3: Severity of anemia and socio-economic class $(\mathrm{N}=89)$.

\begin{tabular}{|c|c|c|c|c|}
\hline \multirow{2}{*}{$\begin{array}{l}\text { Severity } \\
\text { of } \\
\text { anemia }\end{array}$} & \multicolumn{3}{|c|}{ Socio-economic class no. (\%) } & \multirow[b]{2}{*}{$\begin{array}{l}\text { Total } \\
\text { No. }(\%)\end{array}$} \\
\hline & $\begin{array}{l}\text { High } \\
(\%)\end{array}$ & $\begin{array}{l}\text { Middle } \\
(\%)\end{array}$ & $\begin{array}{l}\text { Low } \\
(\%)\end{array}$ & \\
\hline Mild & $5(5.6)$ & $21(23.6)$ & $20(22.5)$ & $46(51.7)$ \\
\hline Moderate & $1(1.1)$ & $16(18.0)$ & $12(13.5)$ & $29(32.6)$ \\
\hline Severe & $1(1.1)$ & $8(9.0)$ & $5(5.6)$ & $14(15.7)$ \\
\hline Total & $7(7.8)$ & $45(50.5)$ & $37(41.7)$ & 89 \\
\hline
\end{tabular}

As shown in Table 3, 89(62.7\%) girls were anemic. Mild, moderate and severe anemia was present in $46(51.7 \%)$, $29(32.6 \%)$ and $14(15.7 \%)$ respectively. Out of these 82 $(92.1 \%)$ girls were from middle and low socioeconomic class.

Table 4: Distribution of body mass index (BMI) $(\mathrm{N}=142)$.

\begin{tabular}{|lcc|}
\hline BMI & No. & Percentage \\
\hline < 19 - Under weight & 63 & 44.4 \\
\hline 19-25- Normal weight & 70 & 49.3 \\
\hline 25-30 - Over weight & 6 & 4.2 \\
\hline$>30$ - Morbid obesity & 3 & 2.1 \\
\hline
\end{tabular}

As shown in Table 4, 70 (49.3\%) girls were in normal weight range, whereas, $72(50.7 \%)$ adolescent girls were either underweight or over weight.

As shown in Table 5, majority of girls 136 (95.8\%) had menstrual problems. Leucorrhoea, PID, ovarian mass, urinary problems, breast problems were present in 42 $(29.6 \%), 24(16.9 \%), 20(14.1 \%), 13(9.2 \%)$ and 12 $(8.5 \%)$ respectively. Injury to genital tract in girls who had history of fall was present in $4(2.8 \%)$ and $1(0.7 \%)$ had history of sexual assault.

\section{Table 5: Types of gynecological problems in adolescent girls $(\mathrm{N}=142) *$.}

\begin{tabular}{|lcc|}
\hline Types of gynecological problems & Total & Percentage \\
\hline Menstrual problems & 136 & 95.8 \\
\hline Leucorrhoea & 42 & 29.6 \\
\hline PID & 24 & 16.9 \\
\hline Ovarian mass & 20 & 14.1 \\
\hline Urinary problems & 13 & 9.2 \\
\hline Breast problems & 12 & 8.5 \\
\hline Injury to genital tract & 04 & 2.8 \\
\hline h/o Sexual assault & 01 & 0.7
\end{tabular}

* More than one complaint in some patients

As shown in Table 6, out of 136 girls who had menstrual problems; dysmenorrhea, menstrual irregularities, primary amenorrhoea and secondary amenorrhoea were present in $72(52.9 \%), 47(34.6 \%), 9(6.6 \%)$ and $8(5.9 \%)$ respectively.

Table 6: Menstrual Problems (N=136).

\begin{tabular}{|c|c|c|c|c|}
\hline $\begin{array}{l}\text { Menstrual } \\
\text { problems }\end{array}$ & $\begin{array}{l}\text { No. } \\
(\%)\end{array}$ & & No. & $\%$ \\
\hline \multirow{3}{*}{ Dysmenorrhea } & \multirow{3}{*}{$\begin{array}{l}72 \\
(52.9)\end{array}$} & Mild & 26 & 36.1 \\
\hline & & Moderate & 29 & 40.3 \\
\hline & & Severe & 17 & 23.6 \\
\hline \multirow{3}{*}{$\begin{array}{l}\text { Menstrual } \\
\text { irregularities }\end{array}$} & \multirow{3}{*}{$\begin{array}{l}47 \\
(34.6)\end{array}$} & $\begin{array}{l}\text { Puberty } \\
\text { menorrhagia }\end{array}$ & 34 & 72.3 \\
\hline & & Polymenorrhoea & 8 & 17 \\
\hline & & Oligomenorrhoea & 5 & 10.6 \\
\hline \multirow{3}{*}{$\begin{array}{l}\text { Primary } \\
\text { amenorrhoea }\end{array}$} & \multirow{3}{*}{$\begin{array}{l}9 \\
(6.6)\end{array}$} & $\begin{array}{l}\text { Imperforate } \\
\text { hymen }\end{array}$ & 7 & 77.8 \\
\hline & & $\begin{array}{l}\text { Blind vagina with } \\
\text { absent uterus }\end{array}$ & 1 & 11.1 \\
\hline & & $\begin{array}{l}\text { Transverse } \\
\text { vaginal septum }\end{array}$ & 1 & 11.1 \\
\hline \multirow{4}{*}{$\begin{array}{l}\text { Secondary } \\
\text { amenorrhoea }\end{array}$} & \multirow{4}{*}{$\begin{array}{l}8 \\
(5.9)\end{array}$} & Systemic illness & 4 & 50 \\
\hline & & PCOD & 2 & 25 \\
\hline & & Stress & 1 & 12.5 \\
\hline & & Malnutrition & 1 & 12.5 \\
\hline
\end{tabular}

\section{DISCUSSION}

During the study period, adolescent girls having gynecological problems were $2.3 \%$. Prakriti $\mathrm{G}$ et al have reported incidence of gynecological problem in adolescent girls as $3.3 \% .^{3}$ In present study, majority of girls $71.1 \%$ were in age group of 16-19 years. Prakriti G et al and Revathi et al have reported $56 \%$ and $62.3 \%$ girls in the age group of 17-19 years respectively. ${ }^{3,4}$ In present study, only $7(4.9 \%)$ belonged to age group of $10-12$ years. This could be because adolescent girls are shy and do not attend routine gynecological OPD. Revathi et al have reported $6.2 \%$ in the $11-13$ years age group. ${ }^{4}$ 
In present study, majority of girls $115(81.0 \%)$ were from urban area. This is because our tertiary care hospital is located in urban area and majority of patients were residing within the city limits.

In present study, only $6(4.2 \%)$ were illiterate, whereas 29 $(20.4 \%)$ had primary education, 48 (33.8\%) had secondary education, $41(28.9 \%)$ had higher secondary education and $18(12.7 \%)$ were studying for graduate degree. A very large segment of the patients were educated at least up to high school and they had more awareness regarding their personal health problems. These findings surely point relation of education and health seeking behavior. Saibaba et al and AS Indupalli et al have reported $13.2 \%$ and $12.4 \%$ of illiterate group, who had adolescent gynecological problems respectively. ${ }^{5,6}$ Saibaba et al reported education status of girls having adolescent gynecological problems and in which $38 \%$ had primary education and $44 \%$ had higher secondary education. ${ }^{5}$ AS Indupalli et al reported $26.4 \%$ had primary education, $36.8 \%$ had secondary education and $24.4 \%$ had higher secondary education. ${ }^{6}$ Since ours is a general hospital, majority of patients came from middle and low socio-economic class. In present study, majority of girls were unmarried. Prakriti $\mathrm{G}$ et al have reported adolescent gynecological problems in $13.3 \%$ and $86.7 \%$ of married and unmarried patients respectively. ${ }^{3}$ Adolescent marriages are still prevalent in our country leading to early sexual activity and its complications like teenage pregnancy, STIs, RTIs, etc. In present study, the mean age of menarche was 12.5 years. Menarche occurred earlier in girls belonging to middle and low socioeconomic class at 12.4 years and at 12.6 years respectively than those belonging to high socioeconomic class, that was at 13.4 years. Jain et al, Verma et al and Sachan et al have reported mean age of menarche as 13.6 years, 13.9 years and 12.8 years respectively. ${ }^{7,8,9}$ The age of menarche is determined by general health, genetic, socioeconomic and nutritional factors. Menarche tends to appear earlier in life as the social, economic and nutritional condition of society improves. ${ }^{10}$

In present study, $89(62.7 \%)$ girls were anemic. Mild, moderate and severe anemia was present in $46(51.7 \%)$, $29(32.6 \%)$ and $14(15.7 \%)$ respectively. Out of these 45 $(50.5 \%)$ and $37(41.7 \%)$ were from middle and low socioeconomic class respectively. Kotecha et al, Kulkarni et al have reported $75.0 \%$ and $90.4 \%$ proportion of anemic patients in middle and lower socioeconomic class respectively. ${ }^{11,12}$ In present study, out of 9 patients of high socioeconomic class, $7(77.8 \%)$ patients had anemia. In high socioeconomic class despite abundance of food availability there is relative lack of awareness regarding nutritive value food and healthy eating habits. In present study, underweight girls with low BMI were 63 (44.4\%). This can be related to the lack of awareness regarding healthy diet and exercise. Prakriti $\mathrm{G}$ et al has reported $69.3 \%$ patients with low BMI. ${ }^{3}$ According to the American academy of family physicians, women who are underweight run risk of malnutrition, fragile bones, a weakened immune system, anemia, hair loss, dry skin and infertility, cardiac problems. Anemia and malnutrition are responsible for menstrual problems like oligomenorrhoea and hypomenorrhoea. ${ }^{13}$

In present study, majority of girls, 136 (95.8\%) had menstrual problems. Leucorrhoea, PID, ovarian mass, urinary problems, breast problems were present in 42 $(29.6 \%), 24(16.9 \%), 20(14.1 \%), 13(9.2 \%)$ and $12(8.5 \%)$ respectively. Injury to genital tract in girls who had history of fall was present in $4(2.8 \%)$ and $1(0.7 \%)$ had history of sexual assault. Prakriti $G$ et al have reported different gynecological problems like menstrual disorders $(60 \%)$, leucorrhoea (10.66\%), infections $(8 \%)$, ovarian cyst $(5.3 \%)$, sexual assault $(2.6 \%)$, teenage pregnancy $(10.6 \%)$ and infertility $(2.6 \%){ }^{3}$ In a study by Kumari A et al, menstrual disorders were the commonest gynecological problems in $74.1 \%$ followed by vaginal discharge in $14.3 \%$ and ovarian tumors in $4.5 \% .{ }^{14}$ In present study, out of $95.8 \%$ of girls who had menstrual problems, dysmennorhoa was present in $72(52.9 \%)$. Prakriti et al, Kumari A et al and Nair et al have reported dysmenorrhea in $17.7 \%, \quad 32.5 \%$ and $63.7 \%$ respectively..$^{3,14,15}$ In present study, out of $72(52.9 \%)$ girls having dysmenorrhea, mild, moderate and severe dysmenorrhoea was present in 26 (36.1\%), 29 (40.3\%) and $17(23.6 \%)$ respectively. Singh et al have reported mild, moderate and severe $63.3 \%, 30.4 \%$ and $6.3 \%$ respectively. ${ }^{16}$ In present study, frequency of dysmenorrhoea in underweight, normal weight and overweight-morbid obesity were 31 (43\%), 36 (50\%) and $5(7 \%)$ respectively. Hence, increased proportion of dysmenorrhoea was found in the normal and low weight group. Attitude of low tolerance among girls in urban areas leads to more premenstrual suffering, heavy flow, socioeconomic losses and loss of qualitative life due to dysmenorrhoea.

In study by Khodakarami $B$ et al, frequency of dysmenorrhoea in underweight, normal-weight and overweight groups was $20.3 \%, 66.7 \%$ and $12.9 \%$, respectively. ${ }^{17}$ Chung et al and Hirata et al have reported dysmenorrhoea in low BMI. ${ }^{18,19}$

In present study, menstrual irregularities were found in $47(34.6 \%)$ patients. Chung et al have reported $47 \%$ patients with menstrual irregularities. ${ }^{18}$ In present study, out of 47 adolescent girls having menstrual irregularities, $34(72.3 \%)$ had puberty menorrhagia where no cause could be ascertained. Polymenorrhoea occurred in 8 (17\%) girls; due to PID in 6 (75\%), due to hematological disorders in $1(12.5 \%)$ and due to hyperthyroidism in 1 $(12.5 \%)$ each of girls. Oligomenorrhoea occurred due to Poly Cystic Ovarian Disease (PCOD) in 5 (10.6\%) of girls. Menstrual abnormalities are more common among younger girls, becoming less frequent as they grow older, 3-5 years after menarche. Third year after menarche the interval between bleeding periods is in the range of 21-34 days, with a flow lasting from 3 to 7 days and a mean menstrual blood loss of $35 \mathrm{ml}$ (range $5-80 \mathrm{ml}$ ). ${ }^{20} \mathrm{In} \mathrm{a}$ 
study by Prakriti G et al, out of $60 \%$ girls having menstrual disorder, $55.6 \%$ had menorrhagia (out of these in $96 \%$ of girls no cause could be ascertained and in $4 \%$ it was due to hypothyroidism) and $2.2 \%$ had complaints of oligomenorrhoea. ${ }^{3}$ In present study, primary amenorrhoea was present in $9(6.6 \%)$. Out of these, 9 patients of primary amenorrhoea, $7(77.8 \%)$ girls had imperforate hymen, $1(11.1 \%)$ had blind vagina with absent uterus. Mayer Rokitansky Kuster Hauser (MRKH) syndrome and $1(11.1 \%)$ had transverse vaginal septum. Secondary amenorrhoea was present in $8(5.9 \%)$ patients.

Causes of secondary amenorrhoea were systemic illness (Abdominal Tuberculosis, Hyperthyroidism, Typhoid and Jaundice) in $4(50 \%)$, PCOD in $2(25 \%)$, psychological stress and malnutrition in $1(12.5 \%)$ each. Revathi et al, Prakriti $\mathrm{G}$ et al and Kumari A et al have reported primary amenorrhoea in $9.8 \%, 6.7 \%$ and $8.4 \%$ respectively and secondary amenorrhoea in $6.1 \%, 17.8 \%$ and $24.1 \%$ respectively. ${ }^{3,4}$ In present study, leucorrhoea was present in $42(29.6 \%)$ girls. Prakriti et al and Goswami $\mathrm{S}$ et al have reported leucorrhoea in $10.7 \%$ and $19.4 \%$ respectively. ${ }^{3,21}$ Leucorrhoea is a frequent and embarrassing problem. Lack of awareness regarding personal hygiene and improper nutrition are causative factors for leucorrhoea. In present study, 20 (14.1\%) girls had ovarian mass. Out of these, 5 (25\%) were follicular cysts, $6(30 \%)$ were hemorrhagic cyst and $1(5 \%)$ was torsion ovarian cyst. Complex ovarian cysts were present in $6(30 \%)$ and dermoid cysts were present in $2(10 \%)$. Prakriti G et al, Kumari A et al and Goswami et al have reported $5.3 \%, 4.5 \%$ and $15.3 \%$ girls with ovarian mass respectively. ${ }^{3,14,21}$ Functional cysts are the most frequently observed cystic masses in the ovary accounting for $20-50 \%$ ovarian tumors in adolescence. ${ }^{22}$

In present study, $12(8.5 \%)$ girls had breast related complaints. Out of these, $9(75 \%)$ were diagnosed as benign breast mass (Fibroadenoma), 2 (16.7\%) as breast abscess and $1(8.3 \%)$ as cyclic mastalgia. Revathi et al4 and Neinstein et al have reported $2.3 \%$ and $3.2 \%$ patients with breast mass respectively. ${ }^{23}$

In present study, problems like Pelvic Inflammatory Disease, urinary tract infection and sexual assault were present in $24(16.9 \%), 13(9.2 \%)$ and 1 (0.7\%) respectively. Sexual assault may lead to lower selfesteem, depression, unwanted pregnancy, sexually transmissible infections and criminal abortion. ${ }^{3}$ Prakriti et al and Kumari A et al have reported $2.7 \%$ and $1.6 \%$ girls who had history of sexual assault respectively. ${ }^{3,14}$ In present study, injury to genital tract was present in 4 $(2.8 \%)$ girls due to history of fall down. Revathi et al have reported $3.9 \%$ with injury to genital tract. ${ }^{4}$

\section{CONCLUSION}

A very small proportion of adolescent girls came to the hospital for health-related issues. Anemia was present in more than half of adolescent girls and almost half of adolescent girls were having either low or high BMI. Menstrual problems were the commonest gynecological problems. In addition, other gynecological problems were leucorrhoea, PID, ovarian mass, UTI, breast problems, genital tract injury and sexual assault. Various factors such as embarrassment, privacy and confidentiality concerns, cultural factors, fear of medical procedures, and judgmental attitude of provider are usually barriers preventing adolescents from visiting a health care facility. Health care to adolescents begins with good communication, maintaining privacy, confidentiality and nonjudgmental attitude. Multispeciality approach with help of physician, surgeon, endocrinologist, dermatologist and psychiatrist is necessary at times while treating an adolescent.

Health education regarding normal physiology, various gynecological problems, importance of nutrition and exercise for adolescents is necessary. In India attempts and success to develop Adolescent friendly health services in public and private system have met with partial success. Hence, an alternative attempt to provide friendly services to adolescents in existing health and medical care service is necessary.

\section{ACKNOWLEDGMENTS}

Authors would like to thank Superintendent of SCL Hospital and Dean of Smt. NHL Municipal Medical College.

Funding: No funding sources

Conflict of interest: None declared

Ethical approval: The study was approved by the Institutional Ethics Committee

\section{REFERENCES}

1. Global accelerated action for the health of adolescents (AA-HA) Available at: http://www.who.int/topics/adolescent_health.

2. Strategy Handbook. Rashtriya Kishor Swasthya Karyakram. Adolescent Health Division Ministry of Health and Family Welfare Government of India. January 2014. Available at: https://nhm.gujarat.gov.in/images/pdf/RKSK_Strateg y_Handbook.pdf.

3. Goswami P, Ahirwar G, Prabha Mishra P, Agrawal V. Adolescent Gynaecological Problems: A Prospective Study. J Evol Med Dent Sci. 2015;4(102):16709-12.

4. Revathi, Karunavanthi, Srilakshmi. Adolescence Gynecological Problems and Legal Acts. IOSR J Dent Med Sci. 2015;14(3):25-8.

5. Saibaba A, Mohan Ram M, Ramana Rao G, Uma Devi ST. Nutritional status of adolescent girls of urban slums and the impact of IEC on their nutritional knowledge and practices. Indian $\mathbf{J}$ Community Med. 2002;27(4):151-6. 
6. Indupalii AS, Health Status of Adolescent Girls in an Urban Community of Gulbarga District, Karnataka. Indian J Pub Health. 2009;3(4):232-4.

7. Jain K, Garg SK, Singh JV, Bhatnagar M, Chopra H, Bajpai SK. Reproductive Health of Adolescent Girls in an Urban Population of Meerut, Uttar Pradesh. Health Population: Perspect Issues. 2009;32(4):2049.

8. Verma PB, Pandya CM, Ramanuj VA, Singh MP. Menstrual Pattern of Adolescent School Girls of Bhavnagar (Gujarat). NJIRM, 2011;2(1):38-40.

9. Sachan B, Idris MZ, Jain S, Kumari R, Singh A. Age at menarche and menstrual problems among schoolgoing adolescent girls of a North Indian district. J Basic Clin Reprod Sci. 2012;1:56-9.

10. Flug D, Largo RH, Proder TO. Menstrual patterns in Adolescent Swiss Girls: a longitudinal study. Ann Hum Biol.1984;11(6):495-508.

11. PV Kotecha, S. Nirupam, PD Karkar. Adolescent Girls' Anaemia control programme, Gujarat, India. Indian J Med Res.2009;130(5):584-9.

12. Kulkarni MV, Durge PM, Kasturwar NB. Prevalence of anemia among adolescent girls in an urban slum. Natl J Community Med. 2012;3(1):108-11.

13. Coleman E. "Low BMI in Women." Healthy Eating | SF Gate, Available at: http://healthyeating.sfgate.com/low-bmi-women7300.html. 20 April 2018.

14. Kumari A. Adolescent Gynaecological Problems: A Clinical Study. J Evol Med Dent Sci. 2013:2(9);1111-5.

15. Nair P, Grover VL, Kannan AT. Awareness and practices of menstruation and pubertal changes amongst unmarried female adolescents in a rural area of East Delhi. Indian $\mathrm{J}$ Community Med. 2007;32(2):156.
16. Singh A, Kiran D, Singh H, Nel B, Singh P, TiwariP. Prevalence and severity of Dysmenorrhea: a problem related to menstruation, among first and second year female medical students. Indian J Physiol Pharmacol, 2008;52(4):389-97.

17. Khodakarami B, Masoomi SZ, Faradmal J, Nazari M, Saadati M, Sharifi F. The Severity of Dysmenorrhea and its relationship with BMI among female adolescent in Hamadan,Iran. J Midwifery Reproduct Health. 2015;3(4);444-450.

18. Chung PW. Menstrual disorders in a Paediatric and Adolescent Gynaecology Clinic: patient presentations and longitudinal outcomes. Hong Kong Med J. 2011;17(5):391-7.

19. Hirata. Realtionship between the frequency of menstrual pain and weight in female adolescent. Nihou Koshu Eisei Zasshi, 2002;49(6):510-24.

20. ACOG Committee on Adolescent Health Care: Menstruation in girls and adolescents using menstrual cycle as a vital sign. Obstet Gynecol. 2006;108(5):1323-8.

21. Sebanti G, Rekha D, Sibani S. A profile of adolescent girls with gynaecological problems. J Obstet Gynecol India. 2005 Jul;55(4):353-5.

22. Kozlowski KJ. Ovarian masses. Adoles Med. 1999; 10:337-50.

23. Neinstein LS, Atkinson J, Diament M. Prevalence and longitudinal study of breast masses in adolescents. J Adoles Health. 1993;14(4):277-81.

Cite this article as: Thaker RV, Madiya AB, Chaudhari HD, Maru JD, Baranda SB. Health profile of adolescent girls visiting obstetrics and gynecology department of tertiary care hospital. Int J Reprod Contracept Obstet Gynecol 2018;7:4678-83. 